\title{
Influence of Parenting Styles and self-efficacy on Academic Achievement of Secondary School Students: A case of Punjab Province Pakistan
}

\author{
Muhammad Rizwan $^{a}$, Xuehong Qi ${ }^{b}$, Muhammad Ali Talha ${ }^{c}$ \\ ${ }^{\text {a }}$ PhD Scholar, School of Education Sciences, Nanjing Normal University, China \\ Email: 31173013@stu.njnu.edu.cn \\ ${ }^{\mathrm{b}}$ Professor, School of Education Sciences, Nanjing Normal University, China \\ ${ }^{c}$ PhD Scholar, School of Education Sciences, Nanjing Normal University, China \\ Email: 31183012@stu.njnu.edu.cn
}

\begin{abstract}
ARTICLE DETAILS
ABSTRACT

History:

The study was conducted to investigate influence of parenting styles on

Accepted 30 April 2021

Available Online June 2021 the academic achievement of secondary school enrolment from the perspective of Pakistan's culture. A cross-sectional research design was used to complete this research. A survey was used as a method of data

\section{Keywords:}

Sustainable Production,

Sustainable Supplier

Management, Sustainable

Performance, Supply Chain

Performance

JEL Classification:

Q01, P27

DOI: $10.47067 /$ reads.v7i2.352 collection accompanied by questionnaires. A multi-stage sampling technique was used to approach the participants. The sample was comprised of 720 students at the secondary level. The outcomes of the study exposed that there is a positive link between parenting styles (responsiveness and control), academic self-efficacy, and academic achievement. The study results indicate a positive impact of parenting style (responsiveness) on the students' academic achievement at the secondary school level. Students reported differences in parenting styles (providing responsiveness and control), academic self-efficacy, and academic achievement. The study found significant differences between various groups of students' mothers' education. Results of the study revealed that responsiveness and control of parenting styles are not substantially different in various regions of the world.
\end{abstract}

(C) 2021 The authors. Published by SPCRD Global Publishing. This is an open access article under the Creative Commons Attribution-

NonCommercial 4.0

Corresponding author's email address: 31173013@stu.njnu.edu.cn

\section{Introduction}

Parenting is a broad term that encompasses all types of parental participation with students as well as the type of relationship that occurs between them. All of the patterns and strategies that parents use to care for their children are referred to as parental styles. In their children's social, emotional, psychological, and intellectual growth and development, parents perform an essential and nurturing role (Knappe, Beesdo-Baum, \& Wittchen, 2010). Kids inherit from their parents' genetic traits and learn personal value structures and relationships with other individuals. Studies (Becker et al., 2010) were 


\section{Review of Economics and Development Studies, Vol. 7 (2) 2021, 215- 229}

conducted to illustrate the impact of parenting on different aspects of adolescents' growth and development. Honicke and Broadbent (2016) domineering, autocratic, uninvolved, and lenient parenting styles. The authoritarian parenting approach is a more flexible kind of parenting in which students are allowed a lot of freedom. However, they are subjected to the restriction, which is accompanied by adequate justifications. Autocratic parenting, often known as authoritarian parenting, is a strict type of parenting.

Authoritative parenting is when parents give and enforce strict rules as if they were heavenly decrees. The parent maintains an uninvolved attitude toward the students in uninvolved parenting. In other words, the pupils' needs are ignored since they are not given the attention they deserve. Permissive parenting is a parenting style in which the adolescent is allowed to disobey parental wishes. It also summarises the classification system that has been established (Darling-Hammond, \& Snyder, 2015).

Parenting strategies have been formed by distinctive cultural conventions, like many other aspects of human psychology. Several studies have investigated the probable connection between parenting and the cultural environment in which a child grows up (Johnson, \& Descartes, 2017). They found that parenting is culturally specific. According to experts, interdependence vs. independence is the basic cultural contrast between collectivist and individualist societies. Traditional societies with parents, fostering support, conformity, family harmony and the coherence of a group, as well as personal humility. Individual culture values independence, personal singularity, personal development, and autonomy, on the other side, (Johnson, Radesky, \& Zuckerman, 2013). Kalenkoski and Pabilonia (2017) Highlighting Autoritarian parenting in a collectivistic culture indicates caring, attentive and involved but also control and domination in an individualistic culture. Behavioral control in Korean culture is viewed as an advantageous parenthood, however behavioural control is viewed in Europeanamerican culture as a terrible parenthood.

Parents from collectivist cultures therefore strive to promote obedience, socially appropriate behaviour, morality and group conformity. Parents from individualistic societies are more focused on children's autonomy, self-expression and self-reliance (Saleem et al., 2015) The cultural diversity of parenthood investigated and concluded that autoritarian parenthood in western countries is seen as undesirable and dysfunctional. It is considered as parental intervene, control and domineering behaviour, but authoritarian and controlled parental care is matched with positive concerns, care and involvement in a collectivist culture. (Saleem et al., 2015).

In Pakistan, the notion of parenting practices is also distinct from Western cultures. Pakistan is a traditional collectivist society dominated by the traditions of culture and religion. A detailed overview of parenting in Pakistan has been provided. According to them, in Pakistani culture, conformity is valued; parents are considered second to God. It is anticipated that children will show their parents a great deal of obedience and harmony. Also, in a traditional collectivist culture, fathers and mothers have different roles to play; mothers are seen to be less controlling and high on warmth, while fathers are supposed to be dominating, controlling, and thinking of showing less participation in their children (Masud et al., 2016). In the practice of parenting styles, there is also a noticeable gender difference where girls are expected to obey their parental control and authority, and boys have more independence and freedom. Parents keep girls in Pakistan in a more overprotective environment, and boys are given more opportunities to socialize and be independent. It is essential to study parenting practices in the cultural context in which people live, keeping in mind many cultural differences (Masud et al., 2016). 


\section{Review of Economics and Development Studies, Vol. 7 (2) 2021, 215- 229}

Parents' parenting styles are classified in a variety of ways. In general, four basic parenting styles based on two key components, namely parental affection (responsive parenting) and parental control (strict parents), have been planned by numerous researchers (Zimmerman et al. 2003). Parents that practise authoritarian parenting have a high amount of control over their children and a poor response to their activities. They expect their children to follow their orders. They frequently punish their children to discourage disobedience. Unlike strict parents, landscape parenting parents were very receptive. Allowing their children more liberty is important, but it must not lead to more conduct. Neglect-predatory parents have low responsiveness and rigour when it comes to parenting. Also, exhibit a contemptuous or neglectful attitude. The parents have a high level of control and reaction in an authoritative parenting style. And their children are socially and academically competent, with little behavioural issues (Stavrulaki, Li, \& Gupta, 2020).

Another viewpoint is that the relationship between various parenting techniques, aspects, and styles and child and adolescent adjustment is the same in both individualistic and collectivist cultures. Child adjustment aspects related with authoritarian and authoritative parenting techniques, styles, and dimensions are consistent across cultures, according to conceptual evaluations of the literature ((Masud et al., 2016).

Academic performance provides a kid with a way to earn significant work and social recognition. Many research were conducted to determine particular characteristics influencing the student's academic success. Academic performance depends on the attendance of the pupils, their family income, their mother-father, their teacher-student relationship, their presence in school, gender and distance from the school. Family and parents are considered an integral system of support accessible to every child and appear to play an important role in the child's growth. While the importance of the home environment cannot be overlooked in the child's development, parents' style for the rearing of their child is the most vital factor affecting the child's development." Academic performance of school students depends on parenting styles along with other conditions, i.e., parents being responsive (supportive and warm), demanding (controlling and supervising), and guidance is given to the students towards their academic performance " Moreover, parents must provide proper nutrition, a safe environment, and guidance to their children to prepare them to fulfill lifelong learning demands (Honicke, \& Broadbent, 2016).

This is seen as a more flexible kind of parenting in which pupils are allowed a great deal of freedom while yet being subjected to limits. This satisfies the limitation while still ensuring that pupils follow the rules set out by the parents (Cherry, 2016). Parents here are attentive to their children's needs and perspectives. Teye and Peaslee (2015) identified conflicted, irritable, afraid, apprehensive, moody, dissatisfied, easily annoyed, passively hostile, vulnerable to stress, aimless, sulky, and unfriendly characteristics in teenagers raised by autocratic parenting techniques. The teenager has been over-powered by an authority, which has resulted in the above circumstance. The results reveal that Asian adolescents with autocratic parents perform better than their American counterparts with authoritarian parents. Autocratic parenting approaches, on the other hand, imply unquestioned parental compliance, parental strictness, which signifies parental care, caring, and participation, all of which contribute to self-motivation (Teye and Peaslee, 2015).

This is referred to as a strict parenting approach. Rules are given and enforced almost to the letter, if not entirely. According to Blaze (2019), authoritarian parenting is when rigid rules are followed as if they were heavenly decrees. The teenager is not told why these regulations must be followed to the letter. Such parents, according to Wolters and Hussain (2015), place a high importance 


\section{Review of Economics and Development Studies, Vol. 7 (2) 2021, 215- 229}

on obedience and compliance, favouring more severe, severe, and severe disciplinary approaches. For girls, on the other hand, the same indirect effect was mostly accomplished through the mediator of classroom participation. In the relationship between severe parenting and academic achievement, combined effortful control and classroom participation have larger indirect benefits for boys than for females. The discussion looks at the possible "paths" that lead from harsh parenting to adolescent academic accomplishment, as well as the gender variations in these "paths." Teachers and parents who want to increase their students' classroom engagement and academic accomplishment should consider the findings of this study (Wang et al., 2018).

Parenting styles are a part of students' academic achievement where they are encouraged and motivated. In Pakistan, all parents want their children to become active and involved in constructive learning scenarios in their educational phase. Healthy parenting styles help the students overcome academic stress, improve self-confidence and develop coping strategies. However, there are particular parents who, despite being educated and intelligent, but their parenting styles are not adequate according to Pakistan's culture. Due to this, their children's academic achievement becomes distorted. It is the parents' responsibility to nurture their students by grooming them in a better environment through their parenting styles. Hence, this study aims to determine the influence of parenting style on academic achievement at the secondary school level.

Following are objectives of the Study:

1. To explore the relationship between parenting styles (responsiveness and control) and students' academic achievement in the perspectives of culture in Pakistan

2. To investigate the impact of parenting styles in the perspective of culture (responsiveness and control) on students' academic performance

3. To examine the mediating effect of self-efficacy between the relationship of parenting styles and academic performance

4. To assess the comparison of parenting styles, self-efficacy, and academic performance between male and female students

5. The establish the differences of research variables to demographic characteristics (father's occupation, mother's occupation, father's education, mother's education, socio-economic status, and area of residence)

6. To describe how culture influences the parenting styles in the province of Punjab Pakistan through interviews

Following are research questions:

1. What is the relationship between parenting styles and students' academic achievement in the perspectives of culture in Pakistan?

2. What is the impact of parenting styles on culture (responsiveness and control) on students' academic performance?

3. What is the mediating effect of self-efficacy between the relationship of parenting styles and academic performance?

4. What is a difference in parenting styles, self-efficacy, and academic performance between male and female students?

5. What are the differences in research variables to demographic characteristics; father's occupation, mother's occupation, father's education, mother's education, socio-economic status, and residence area?

6. How culture influences the parenting styles in the province of Punjab Pakistan 


\section{Review of Economics and Development Studies, Vol. 7 (2) 2021, 215- 229}

Following are hypotheses of the study:

Ho1: There is no significant relationship between parenting styles (responsiveness, control), academic self-efficacy, and academic achievement.

Ho2: There is no significant impact of parting styles (responsiveness and control) and academic achievement

Ho3: There is no significant mediating effect of self-efficacy between the relationship of parenting styles and academic achievement

Ho4: There is no significant difference in demographic variables in term of parenting styles, academic self-efficacy, and academic achievement

\section{Method}

\subsection{Research Design}

The nature of study was quantitative that was completed though correlational research design. Survey was conducted to collect the data by using questionnaire.

\subsection{Participants}

This study's participants were secondary school students from Punjab, a Pakistani region. To draw a sample from the population, multistage sampling was used. Three divisions were chosen from a total of nine, one each from the Punjab's southern, middle, and northern regions. Each division was assigned one developed and one underdeveloped district, for a total of $6\left(3^{*} 2=6\right)$. Two girls and two boys secondary schools were chosen from each district, for a total of 24 secondary schools $(6 * 4=24)$. Each division had 240 pupils because ten pupils from each division were chosen $\left(24^{*} 10=240\right)$. A total of 720 people were chosen from three divisions. There were 720 students in the study sample, including 375 males and 345 females.

\subsection{Instruments}

1. The scale of Parenting Style

2. Academic Performance Questionnaire

3. Academic Self-efficacy Scale

\subsubsection{Scale of Parenting Style (Gafor, 2014)}

Different researchers developed parenting style tools in other cultures; some recognize only three parenting types, and some are designed for parents rather than children. So, in the eastern parenting practices and cultural context, the authors sense the need for a parenting scale continuum.

\subsubsection{Scale of Parenting Style}

This scale is used for measuring higher secondary school students' perceived parenting styles. Based on Baumrind's theories (1971) and the dimensions proposed by Maccoby and Martin, the draught scale was developed (1983). The final scale consists of 38 items, 19 of which are for parental responsiveness measurement and 19 for parental control measurement.

\subsubsection{Academic Performance Questionnaire (Yasmin \& Kiani, 2019)}

The students' academic performance was measured through the Academic Performance Questionnaire (Yasmin \& Kiani, 2019), developed after discussing it with a panel of experts. It was based on performance indicators and consisted of 38 items with Academic Motivation (6 items), Communication skills (6 items), Learning skills (6 items), Creativity (6 items), Positive Attitude (8 items), Study skills (6 items). It was a responsive-point-point Likert scale ranging from Strongly Agree to Strongly Disagree. There were marked reversely; these include serial numbers 5, 9, 10, 20, 26, 29, 
and 31.

\subsubsection{Academic Self-efficacy Scale (Byrne, 2014; Matoti, 2011)}

In assessing academic self-efficacy, the study adopted the instrument developed by Byrne (2014) and Matoti (2011). A total of 20 items were featured in the survey questionnaire using a five-point Likert scale ranging from strongly disagrees to strongly agree. A set of academics reviewed the questions of each of the constructs to ensure comprehensiveness and clarity. The questionnaire was then initiated to pilot test by 30 undergraduates to ensure further clarity.

\subsection{Procedures}

Permission was taken from the Head teachers to collect the data from the secondary schools. Informed consent was received from the respondents. A booklet was given to students that were comprised of the questionnaires. Instructions were written on the first page of the brochure; for any inconvenience, the researcher was presented at the time of data collected to help the participants. It was assured that their information would remain confidential and only will be used for the study.

\subsection{Data Analysis}

Data were analyzed by applying descriptive as well as inferential statistics. Collected data were entered into the Statistical Package of Social Science (SPSS-23). Following tests were used to test hypotheses (inferential statistics); Pearson Correlation for investigating the relationship between variables, t-test for independent samples to compare the variables (parenting styles, self-efficacy, and academic achievement) among Pakistan students. A Linea regression was utilized to determine the impact of parenting styles (responsiveness and control) on academic achievement. ANOVA was used to compare the mean values concerning different demographic characteristics. The mediating effect was drawn by employing Integrating Mediation and Moderation Analysis: PROCESS by Andrew F. Hayes (2013) was used and the VAF formula of Smart PLS. 
Review of Economics and Development Studies, Vol. 7 (2) 2021, 215- 229

3. Results

Table 1: Demographic Variables

\begin{tabular}{|c|c|c|c|}
\hline Name & Frequency & Percent & Cumulative Percentage \\
\hline \multicolumn{4}{|l|}{ 1. Gender } \\
\hline Male & 375 & 52.1 & 52.1 \\
\hline Female & 345 & 47.9 & 100.0 \\
\hline \multicolumn{4}{|l|}{ 2. Region } \\
\hline Northern Punjab & 240 & 33.3 & $33 \cdot 3$ \\
\hline Central Punjab & 240 & 33.3 & 66.7 \\
\hline Southern Punjab & 240 & 33.3 & 100.0 \\
\hline \multicolumn{4}{|c|}{ 3. Father Occupation } \\
\hline Governmental & 340 & 47.2 & 47.2 \\
\hline Non-governmental & 380 & 52.8 & 100.0 \\
\hline \multicolumn{4}{|c|}{ 4. Mother Occupation } \\
\hline Governmental & 306 & 42.5 & 42.5 \\
\hline Non-governmental & 414 & 57.5 & 100.0 \\
\hline \multicolumn{4}{|c|}{ 5. Father Education } \\
\hline Uneducated & 287 & 39.9 & 39.9 \\
\hline Primary & 159 & 22.1 & 61.9 \\
\hline Secondary & 242 & 33.6 & 95.6 \\
\hline Master & 32 & 4.4 & 100.0 \\
\hline \multicolumn{4}{|c|}{ 6. Mother Education } \\
\hline Uneducated & 265 & 36.8 & 36.8 \\
\hline Primary & 222 & 30.8 & 67.6 \\
\hline Secondary & 72 & 10.0 & 77.6 \\
\hline Bachelor & 97 & 13.5 & 91.1 \\
\hline Master & 64 & 8.9 & 100.0 \\
\hline
\end{tabular}

Table 2: Cronbach's Alpha Reliability

\begin{tabular}{|l|l|l|}
\hline Variables & Number of Items & Cronbach's Alpha \\
\hline Parenting Style & 38 & .982 \\
\hline Academic Achievement & 38 & .977 \\
\hline Self-efficacy & 20 & .965 \\
\hline
\end{tabular}

Table 3: Correlation Matrix among Secondary School Students (Parenting Styles, Academic Self efficacy and Academic Achievement

\begin{tabular}{|l|l|l|l|l|l|l|l|}
\hline & & Mean & Std. Deviation & 1 & 2 & 3 & 4 \\
\hline 1 & RPS & 71.5208 & 16.03628 & 1 & $.992^{* *}$ & $.907^{* *}$ & $.928^{* *}$ \\
\hline 2 & CPS & 71.8528 & 15.37118 & & 1 & $.899^{* *}$ & $.938^{* *}$ \\
\hline 3 & ASE & 72.2708 & 15.36565 & & & 1 & $.897^{* *}$ \\
\hline 4 & AA & 134.1083 & 26.79707 & & & & 1 \\
\hline
\end{tabular}

Note,

RPS responsiveness parenting style

CPS control parenting style 
ASE academic self-efficacy

AA academic achievement

Table: 4 Standard Regression Model showing impact of Parenting Style (Responsiveness) on Academic Achievement

\begin{tabular}{|l|l|l|l|l|l|}
\hline Predictor & B & Std. Error & Beta & t-test & P-value \\
\hline (Constant) & 23.222 & 1.705 & & 13.619 & .000 \\
\hline PS & 1.550 & .023 & .928 & 66.645 & .000 \\
\hline
\end{tabular}

$\mathrm{R} 2=.861$, Adjusted R2 $=.861,(\mathrm{~F}(1,719)=4441.569, \mathrm{p}<0.05)$

Table 5: Standard Regression Model showing impact of Parenting Style (Control) on Academic Achievement

\begin{tabular}{|l|l|l|l|l|l|}
\hline Predictor & B & Std. Error & Beta & t-test & P-value \\
\hline (Constant) & 16.604 & 1.656 & & 10.025 & .000 \\
\hline PC & 1.635 & .023 & .938 & 72.545 & .000 \\
\hline
\end{tabular}

$\mathrm{R} 2=.880$, Adjusted R2 $=.880,(\mathrm{~F}(1,719)=5262.723, \mathrm{p}<0.05)$

Table 6: The significant impact of Parenting Style (Responsiveness) on Academic Achievement is mediated by Academic Self-efficacy

\begin{tabular}{|l|l|l|l|l|}
\hline Showing the Direct, Indirect effect and Total effect in prediction of Academic Achievement \\
\hline $\begin{array}{l}\text { Independent } \\
\text { variable }\end{array}$ & Direct effect & Indirect effect & Total Effect \\
\hline RPS on AA & 1.0763 & .4741 & 1.8173 \\
\hline $\begin{array}{l}\text { Showing the mediating effect of Academic Self-efficacy between the relationship of Parenting } \\
\text { Style (Responsiveness) and Academic Achievement }\end{array}$ & Total Effect & VAF & Assessment \\
\hline Relationship & Indirect effect & 1.8173 & & Partial Mediation \\
\hline RPS $>$ ASE >AA & .4741 &
\end{tabular}

Table 7: The significant impact of Parenting Style (Control) on Academic Achievements is mediated by Academic Self-efficacy

\begin{tabular}{|l|l|l|l|l|}
\hline \multicolumn{6}{|l|}{ Showing the Direct, Indirect effect and Total effect in prediction of Academic Achievement } \\
\hline $\begin{array}{l}\text { Independent } \\
\text { variable }\end{array}$ & Direct effect & Indirect effect & Total Effect \\
\hline CPS on AA & 1.1964 & .4390 & 1.6354 \\
\hline $\begin{array}{l}\text { Showing the mediating effect of Academic Self-efficacy between the relationship of Parenting } \\
\text { Style (Control) and Academic Achievement }\end{array}$ & Total Effect & VAF & Assessment \\
\hline Relationship & Indirect effect & 1.8173 & $26.84 \%$ & Partial Mediation \\
\hline CPS $>$ ASE $>$ AA & .4390 &
\end{tabular}


Table 8: Mean, Standard Deviation, t-value and scores of Perceived Parental Styles (Responsiveness, Control), Academic Self-efficacy and Academic Achievement with respect to the gender of students $(n=720)$.

\begin{tabular}{|l|l|l|l|l|l|l|l|}
\hline Variable & Gender & $\mathrm{N}$ & $\mathrm{M}$ & Std. Deviation & Df & t-test & p-value \\
\hline \multirow{2}{*}{ RPS } & Male & 375 & 81.0347 & 11.37223 & 718 & 21.116 &. ooo \\
& Female & 345 & 61.1797 & 13.81931 & & & \\
\hline \multirow{2}{*}{ CPS } & Male & 375 & 80.7973 & 11.02896 & 718 & 20.472 & .000 \\
& Female & 345 & 62.1304 & 13.40070 & & & \\
\hline SE & Male & 375 & 81.0373 & 9.97637 & 718 & 19.849 & .000 \\
& Female & 345 & 62.7420 & 14.50642 & & & \\
\hline \multirow{2}{*}{ AA } & Male & 375 & 149.3787 & 21.99333 & 718 & 19.812 & .000 \\
& Female & 345 & 117.5101 & 21.08291 & & & \\
\hline
\end{tabular}

Table 9: Mean, Standard Deviation, t-value and scores of Perceived Parental Styles (Responsiveness, Control), Academic Self-efficacy and Academic Achievement with respect to the Father's Occupation $(n=720)$.

\begin{tabular}{|c|c|c|c|c|c|c|c|}
\hline Variable & Father Occupation & $\mathrm{N}$ & M & $\begin{array}{l}\text { Std. } \\
\text { Deviation }\end{array}$ & Df & t-test & $\mathrm{p}$-value \\
\hline RPS & $\begin{array}{l}\text { Governmental } \\
\text { Non-Governmental }\end{array}$ & $\begin{array}{l}340 \\
380\end{array}$ & $\begin{array}{l}75.2912 \\
68.1474\end{array}$ & $\begin{array}{l}14.29175 \\
16.76311\end{array}$ & 718 & 6.117 & .000 \\
\hline CPS & $\begin{array}{l}\text { Governmental } \\
\text { Non-Governmental }\end{array}$ & $\begin{array}{l}340 \\
380\end{array}$ & $\begin{array}{l}75 \cdot 6912 \\
68.4184\end{array}$ & $\begin{array}{l}12.97929 \\
16.50781\end{array}$ & 718 & 6.518 & .000 \\
\hline SE & $\begin{array}{l}\text { Governmental } \\
\text { Non-Governmental }\end{array}$ & $\begin{array}{l}340 \\
380\end{array}$ & $\begin{array}{l}72.4029 \\
72.1526\end{array}$ & $\begin{array}{l}16.10143 \\
14.69650\end{array}$ & 718 & .218 & .827 \\
\hline AA & $\begin{array}{l}\text { Governmental } \\
\text { Non-Governmental }\end{array}$ & $\begin{array}{l}340 \\
380\end{array}$ & $\begin{array}{l}141.4941 \\
127.5000\end{array}$ & $\begin{array}{l}23.27437 \\
28.01832\end{array}$ & 718 & 7.241 & .000 \\
\hline
\end{tabular}


Review of Economics and Development Studies, Vol. 7 (2) 2021, 215- 229

Table 10: Mean, Standard Deviation, t-value and scores of Perceived Parental Styles (Responsiveness, Control), Academic Self-efficacy and Academic Achievement with respect to the Mother's Occupation $(\mathbf{n}=720)$.

\begin{tabular}{|l|l|l|l|l|l|l|l|}
\hline Variable & Mother Occupation & $\mathrm{N}$ & $\mathrm{M}$ & $\begin{array}{l}\text { Std. } \\
\text { Deviation }\end{array}$ & Df & t-test & p-value \\
\hline RPS & Governmental & 306 & 73.8007 & 14.29175 & 718 & 3.302 & .001 \\
& Non-Governmental & 414 & 69.8357 & 16.76311 & & & \\
\hline CPS & Governmental & 306 & 74.6373 & 12.97929 & 718 & 4.228 & .000 \\
& Non-Governmental & 414 & 69.7947 & 16.50781 & & & \\
\hline SE & Governmental & 306 & 70.5196 & 16.10143 & 718 & -2.640 & .008 \\
& Non-Governmental & 414 & 73.5652 & 14.69650 & & & \\
\hline AA & Governmental & 306 & 141.4941 & 138.3856 & 718 & 3.715 & .000 \\
& Non-Governmental & 414 & 127.5000 & 130.9469 & & & \\
\hline
\end{tabular}

Table 11: Analysis of variance (one way) showing the differences of Perceived Parental Styles (Responsiveness, Control), Academic Self-efficacy and Academic Achievement in relation to Father's Education $(n=720)$.

\begin{tabular}{|c|l|l|l|l|l|}
\hline & Sum of Squares & df & Mean Square & F & p-value \\
\hline RPS Between Groups & 9886.734 & 3 & 3295.578 & 13.483 & .000 \\
Within Groups & 175012.953 & 716 & 244.431 & & \\
Total & 184899.688 & 719 & & & \\
\hline $\begin{array}{c}\text { CPC Between Groups } \\
\text { Within Groups }\end{array}$ & 7346.303 & 3 & 2448.768 & 10.787 & ooo \\
Total & 162534.091 & 716 & 277.003 & & \\
\hline SE Between Groups & 169880.394 & 719 & & & 0oo \\
Within Groups & 16895.950 & 3 & 5631.983 & 26.380 & \\
$\quad$ Total & 152862.238 & 716 & 213.495 & & 0oo \\
\hline $\begin{array}{c}\text { AA Between Groups } \\
\text { Within Groups }\end{array}$ & 169758.187 & 719 & & 24.376 & \\
Total & 47845.494 & 3 & 15948.498 & & \\
\hline
\end{tabular}


Review of Economics and Development Studies, Vol. 7 (2) 2021, 215- 229

Table 12: Analysis of variance (one way) showing the differences of Perceived Parental Styles (Responsiveness, Control), Academic Self-efficacy and Academic Achievement in relation to Mother's Education $(\mathbf{n}=\mathbf{7 2 0})$.

\begin{tabular}{|c|l|l|l|l|l|}
\hline & Sum of Squares & df & Mean Square & F & p-value \\
\hline RPS Between Groups & 58106.314 & 4 & 14526.578 & 81.917 & .000 \\
Within Groups & 126793.374 & 715 & 177.333 & & \\
Total & 184899.688 & 719 & & & \\
\hline CPC Between Groups & 46057.460 & 4 & 11514.365 & 66.488 & ooo \\
Within Groups & 123822.934 & 715 & 173.179 & & \\
Total & 169880.394 & 719 & & & \\
\hline SE Between Groups & 76497.769 & 4 & 19124.442 & 146.621 & ooo \\
Within Groups & 93260.419 & 715 & 130.434 & & \\
Total & 169758.188 & 719 & & & 000 \\
\hline $\begin{array}{c}\text { AA Between Groups } \\
\text { Within Groups }\end{array}$ & 192886.887 & 4 & 48221.722 & 106.608 & \\
Total & 323414.663 & 715 & 452.328 & & \\
\hline
\end{tabular}

Table 13: Analysis of variance (one way) showing the differences of Perceived Parental Styles (Responsiveness, Control), Academic Self-efficacy and Academic Achievement in relation to Divisions $(\mathbf{n}=720)$.

\begin{tabular}{|c|l|l|l|l|l|}
\hline & Sum of Squares & df & Mean Square & F & p-value \\
\hline RPS Between Groups & 1411.858 & 2 & 705.929 & 2.759 & .064 \\
Within Groups & 183487.829 & 717 & 255.911 & & \\
Total & 184899.688 & 719 & & & \\
\hline CPS Between Groups & 1069.878 & 2 & 534.939 & 2.272 & .104 \\
Within Groups & 168810.517 & 717 & 235.440 & & \\
Total & 169880.394 & 719 & & & \\
\hline SE Between Groups & 433.225 & 2 & 216.612 & .917 & .400 \\
Within Groups & 169324.963 & 717 & 236.158 & & \\
Total & 169758.188 & 719 & & & \\
\hline AA Between Groups & 9961.900 & 2 & 4980.950 & 7.053 & .001 \\
Within Groups & 506339.650 & 717 & 706.192 & & \\
Total & 516301.550 & 719 & & & \\
\hline
\end{tabular}

\section{Discussions}

The literature widely acknowledges the academic pressures on students' academic accomplishments and achievements have their price, especially in terms of stress. Parents play a huge role in their children's academic accomplishment, butut a great deal of negligence is observed concerning these issues. When it comes to academics, parents have set certain expectations and demands for their children to meet their expectations. Still, such enthusiasm is not seen when it comes to other activities or competitions of life. Parents perceive academic achievements as the best achievement their child can accomplish. However, this results in parents paying less attention to nonacademic skills or accomplishments. A lack of attention means a lack of expectations study were extreme constructs study: parental styles (responsiveness and control), academic achievement, and self-efficacy. 


\section{Review of Economics and Development Studies, Vol. 7 (2) 2021, 215- 229}

Study reveals the there is a positive relationship between parenting styles (responsiveness and control), academic self-efficacy, and academic achievement. The results of the study indicate a positive impact of parenting style (responsiveness) on the students' academic achievement at a higher secondary school level. The student whose parenting style is responsiveness predicts academic achievement among their children at the higher secondary school level. The findings of study suggested a positive impact of parenting style (control) on the students' academic achievement at the higher secondary school level. The student whose parenting style is responsiveness predicts academic achievement among their children at the higher secondary school level. Study shows the direct effect, indirect effect, and total effect calculated for parenting style and academic achievement by taking selfefficacy as a mediator. There is partial mediation as parenting style has a significant relation to academic achievement without a mediator(self-efficacy), but with mediator variable, its impact heightens as a highly significant and indirect effect in our results are significant but weak; therefore, we can say The significant impact of Parenting Style (Responsiveness and control) on Academic Achievement is mediated by Academic Self-efficacy. After analyzing the data, it is identified that the perception of RSP has founded higher among male students than females. Simultaneously, the perception of parenting style is also investigated with a significant difference between male and female students. The level of CPS is founded greater among males than females whose average scores so, the outcomes of the study are significant on the perspectives of comparison of research variables with demographic characteristics of participants' gender. Furthermore, the comparison of SE is assessed with a significant difference between males and females, and the level of SE is more among males than females. Consequently, all the variables are identified as significant and founded, their level at higher values among male students than females. The basis for evaluated parental styles toward males is that parents view them as an investment for their old age or after plan, parents want their sons to support and take care of them they posse more attention in bringing up their sons. It might be why that means difference was found to be significant toward male gender in their perception of self-efficacy and academic achievement compared to females. After analyzing the data, it is identified that the perception responsiveness parenting styles (RPS), control-parenting style (CPS) and academic achievements (AA) is higher among sibling of the government sector as compared to siblings of non-government sectors. The comparison of self-efficacy was non-significant concerning the father's occupation as a government employee or non-government employee. After analyzing the data, it is identified that the perception of RPS is founded higher among students of government employees mothers compared to students of nongovernment occupational mothers. Simultaneously, the perception of parenting style is also investigated with a significant difference between government and non-government employees. The level of CPS is founded greater among government employees than non-government employees occupied mothers. Furthermore, SES comparison is assessed with a significant difference, more toward non-government employees' children compared to government employees' children. Academic achievement is reported high among siblings of government employees. Consequently, variables founded higher toward government employees children are parenting styles (responsiveness and control) and academic achievement. At the same time, self-efficacy is reported high among students of non-government employees as about mother occupation. It became clear from the current study that difference in father occupation has an impact on responsive parenting style (RPS), control parenting style (CPS), self-efficacy (SE), and academic achievement (AA). The study shows the multiple comparisons of differences in Perceived Parental Styles (Responsiveness, Control), Academic Selfefficacy, and Academic Achievement in relation to Mother's Education show the significant difference. The findings of the study reveal that there are significant mean differences among different groups of study variables. Perception of control and responsive parenting styles, academic self-efficacy, and academic achievement related to mothers' education among students within groups and between groups. The study's findings describe that reported more sensitivity to parental styles, academic self- 


\section{Review of Economics and Development Studies, Vol. 7 (2) 2021, 215- 229}

efficacy, and academic achievement in relation to mother's education among within groups and between groups.

Parents never use only one type of parenting style; instead, parents adopt many different styles. Culture has a deep impact on the parenting style. Culture is embedded in history, which was rooted millions of years ago. Asian culture is different from western culture as in Asia; each country has its own culture. The religion of any country influences culture. Even so, the cultures of different neighboring countries have some basic similarities. Even though all these cultural differences exist, the parenting styles are similar everywhere. The core elements of parenting styles are the same, but variations in parenting styles are due to religious and cultural impact. Therefore, in the presenting study, the researcher attempts to identify the parenting styles and their expression from the parents' perspective. In Pakistan, there is literature available from the perspective of students and children. Even though it is not enough, still researches were conducted to address their issues.

\section{Conclusion}

The study was designed to investigate the influence of parenting styles on secondary school students' academic achievement: a case study of Punjab Province, Pakistan. Cronbach's alpha suggests that the questionnaires have high internal consistency; a significant relationship exists among study variables. There is a positive impact of responsiveness and control parenting style on students' academic achievement. A weak significant mediating effect of self-efficacy was found between the parenting styles (responsiveness and control) and academic achievement. Male students reported more degree of parental responsiveness and control, self-efficacy, and academic achievement. The study's outcomes are significant in comparing research variables with demographic characteristics of father occupation (government or non-government), mother occupation. Father occupation (government and non-government) has a significant impact on academic achievement, responsive and control parenting styles while not impacting students' self-efficacy. A significant difference between father and mother occupation was found on the study variable. Differences at the division level are not predisposed to the perception of Parental Styles (Responsiveness, Control), and academic achievement is significant, but Academic Self-efficacy is not found significant statistically.

The culture widely influences parenthood in our country. Many aspects of the parenting styles are adopted from the old cultural values and teachings passed down from generation to generation. Religion plays a minor role in parenthood as well. Respecting parents, obeying parents, raising the child, helping parents in old age, etc., are all religious influences while unnecessary strictness on the child, blind trust in parents, forcing decisions on the child, and making children's decisions are all due to cultural influences. Many of the practices in parenthood, which stem from the cultural role, harm the child. Many people realize this now, but there is a lack of proper awareness about the deteriorating effects of individual parenting styles like unnecessary strictness, not supporting a child, not letting a child decide for them, not communicating with the child, and not having healthy relations with a child. There is a need for people to realize which parenting styles are suitable for healthy child growth and which are not.

\section{Practical Implications}

1. The study's scope was geographically broad as it composed a sample from different divisions of Pakistan.

2. The research has both theoretical and practical applications. To increase children's academic achievement and self-efficacy, the study focuses on parenting styles as these factors are of great significance for practical implication. 
3. It helps to understand better Pakistan's cultural, ethical, and social influences on academic achievements and self-efficacy from parents' and students' perspectives.

4. It highlights common parenting styles common in Pakistan.

5. This study uses ethics to improve students' academic achievements and self-efficacy in higher secondary classes.

6. It helps in understanding the parents' psychology.

7. Parents are the ones who best understand their children. By working in cohesion with them, a more in-depth view of parenting styles and practices is obtained.

8. Pakistan has young adults (30 million aged 15-24) responsible for the country's development, and it is required to provide them the best possible aid to deal with the future.

9. The use of mixed methods enhanced this research project's quality, which has provided exciting results that would be useful for parents involved in the mathematics education of their children.

\section{Limitations of the research}

1) A larger sample would provide better and more general results.

2) The study was conducted in a smaller area over a limited period. This means that the study is unable to predict academic achievements and self-efficacy in other states.

3) Stress, depression, and anxiety among students were not considered when studying this study's parenting styles and academic achievements.

4) The evolution of parenting styles' impact on self-efficacy and academic achievement was not carried with a longitudinal design.

5) The time was too short for performing this analysis and effectively and efficiently analyzes the results.

6) There was no consideration of problem focusing or emotion focus strategies for this current study.

7) The study was conducted in a period of a pandemic lockdown (COVID-19). Such variables on academics and self-efficacy can alter the results from those in more amicable conditions.

8) Culture impacts parenting; the variance in culture can have various results in terms of academics and self-efficacy, which may also vary from individual to individual.

9) There is restrain of money and resources for this study.

\section{Recommendations for future research}

1. In the Future, the research should be carried out on larger scales.

2. Psychiatric disorders especially stress, depression, and anxiety among students, should be considered when studying parenting styles and academic achievements.

3. Theoretically, the best environment for a child would be one in which there are clear communications of expectations on the side of the parent and admittance of perceived weaknesses on both parents' and child's part. Future researches should test this theory.

4. Future research should study the impact of change in the academic environment on the variables.

5. Problem-focused and emotion-focused strategies should be studied on academic achievements and self-efficacy among students.

6. Changes in educational policies and curriculum should also be studied in detail.

7. Future studies should incorporate many variables like the teachers' behavior, parents' and teachers' perspectives on the child, and the students' well-being (accounting for illness when seeing academic achievements).

The change in self-efficacy throughout the academic course should be studied. This is to consider the increase in stress during proximity of examinations and its effects on a child's academic performance. 


\section{References}

Becker, K. D., Ginsburg, G. S., Domingues, J., \&Tein, J. Y. (2010). Maternal control behavior and locus of control: Examining mechanisms in the relation between maternal anxiety disorders and anxiety symptomatology in children. Journal of abnormal child psychology, 38(4), 533-543.

Blaze, P. (2019). The Effects of Social Support and Self-Efficacy on Academic Performance (Doctoral dissertation).

Cherry, K. (2016). Erik Erikson's stages of psychosocial development the eight stages of psychosocial development. Verywell.com, Psychology.

Darling-Hammond, L., \& Snyder, J. (2015). Meaningful learning in a new paradigm for educational accountability: An introduction. education policy analysis archives, 23, 7.

Honicke, T., \& Broadbent, J. (2016). The influence of academic self-efficacy on academic performance: A systematic review. Educational Research Review, 17, 63-84.

Honicke, T., \& Broadbent, J. (2016). The influence of academic self-efficacy on academic performance: A systematic review. Educational Research Review, 17, 63-84.

Johnson, E. J., \& Descartes, C. H. (2017).Parental influence on academic achievement among the primary school students in Trinidad. Early Child Development and Care, 187(7), 1221-1227.

Johnson, L., Radesky, J., \& Zuckerman, B. (2013). Cross-cultural parenting: Reflections on autonomy and interdependence. Pediatrics, 131(4), 631-633.

Kalenkoski, C. M., \& Pabilonia, S. W. (2017). Does high school homework increase academic achievement?. Education Economics, 25(1), 45-59.

Knappe, S., Beesdo-Baum, K., \&Wittchen, H. U. (2010). Familial risk factors in social anxiety disorder: calling for a family-oriented approach for targeted prevention and early intervention. European child \& adolescent psychiatry, 19(12), 857-871.

Masud, H., Ahmad, M. S., Jan, F. A., \& Jamil, A. (2016). Relationship between parenting styles and academic performance of adolescents: mediating role of self-efficacy. Asia Pacific Education Review, 17(1), 121-131.

Stavrulaki, E., Li, M., \& Gupta, J. (2020). Perceived parenting styles, academic achievement, and life satisfaction of college students: the mediating role of motivation orientation. European Journal of Psychology of Education, 1-25.

Teye, A. C., \&Peaslee, L. (2015, December).Measuring educational outcomes for at-risk children and youth: Issues with the validity of self-reported data. In Child \& Youth Care Forum (Vol. 44, No. 6, pp. 853-873).Springer US.

Wang, M., Deng, X., \& Du, X. (2018). Harsh parenting and academic achievement in Chinese adolescents: Potential mediating roles of effortful control and classroom engagement. Journal of school psychology, 67, 16-30.

Wolters, C. A., \&Hussain, M. (2015).Investigating grit and its relations with college students' selfregulated learning and academic achievement. Metacognition and Learning, 10(3), 293-311

Zimmerman, B. J. (2000). Self- 